\title{
IMPROVING DIMENSIONAL STABILITY OF INJECTION MOLDED WOOD PLASTIC COMPOSITES USING COLD AND HOT WATER EXTRACTION METHODS
}

\author{
Ferhat Ozdemir', Nadir Ayrilmis ${ }^{2, \bullet}$, Alperen Kaymakci, Jin Heon Kwon ${ }^{4}$
}

\begin{abstract}
Dimensional stability of wood plastic composites (WPCs) made from polypropylene and pine wood flour with and without coupling agent was investigated. The pine wood flour was prepared from wood chips which had been immersed, respectively, in boiling water for $1 \mathrm{~h}, 3 \mathrm{~h}$, and $5 \mathrm{~h}$ or in distilled water for 1 day, 3 days, and 5 days at room temperature. It was found that thickness swelling (TS) and water absorption (WA) of the WPCs made using extracted wood were lower than those of WPCs produced with unextracted wood. The TS and WA values of WPCs decreased with extraction duration both for cold and hot water extraction. The effect of hot water extraction on the TS and WA properties of the WPCs was more pronounced than cold water extraction.
\end{abstract}

Keywords: Cold water extraction, dimensional stability, hot water extraction, wood plastic composite.

\section{INTRODUCTION}

Wood plastic composites (WPCs) have been used in construction and building applications such as decking, siding, and fencing. Exterior applications, especially under humid conditions, require high durability and resistance to water. The morphological and chemical properties of the raw materials used to produce wood plastic composites are important variables for the final properties of the composite; particularly the dimensional stability (Andrusyk et al. 2008). The use of wood particles as filler in the plastic matrix can result in a stiffer and reduced cost for the WPCs. Although the hydrophobic thermoplastic matrix slows the uptake of water and moisture absorption remain important concerns for WPCs (Hosseinaei et al. 2012a). Wood filler is primarily responsible for thickness swelling (TS) and water absorption (WA) of the WPCs. Wood is a hydrophilic porous composite of cellulose, lignin, and hemicellulose polymers that are rich in functional groups such as hydroxyls, which readily interact with water molecules by hydrogen bonding and thus induce the swelling. For this reason, WPCs have potential to take up water under humid conditions due to the presence of numerous hydroxyls in particular hemicellulose and cellulose.

\footnotetext{
${ }^{1}$ Assistant Prof., Ph.D. Kahramanmaras Sutcu Imam University, Forestry Faculty. Department of Forest Industry Engineering. 46100 Kahramanmaraş, Turkey. ferhatozd@ksu.edu.tr

${ }^{2}$ Associate Prof., Ph.D. Istanbul University, Forestry Faculty. Department of Wood Mechanics and Technology. Bahcekoy, Sariyer, 34473, Istanbul, Turkey. ${ }^{3} \mathrm{Ph}$.D. Student. Istanbul University, Forestry Faculty. Department of Wood. Mechanics and Technology. Bahcekoy, Sariyer, 34473, Istanbul, Turkey. alperen. kaymakci@istanbul.edu.tr

${ }^{4}$ Prof., Ph.D. Department of Forest Biomaterials Engineering, College of Forest and Environmental Sciences, Kangwon National University 200-701

Chuncheon, Republic of Korea. kwon@kangwon.ac.kr

^Corresponding author: nadiray@istanbul.edu.tr

Received: 04.07.2013 Accepted: 12.11.2013
} 
The influence of cold or hot water treated wood on the dimensional stability of wood-based panels such as particleboard and strandboard has been extensively investigated in previous studies (Hosseinaei et al. 2012a, Paredes et al. 2008, Iswanto et al. 2010, Liu et al. 2012). In these studies, it was reported that wood-based panels produced with extracted wood materials showed significantly lower swelling ratio (Hosseinaei et al. 2012b, Paredes et al. 2008, Iswanto et al. 2010). Liu et al. (2012) reported that extractives and products of hemicelluloses could be readily removed from wood by hot water treatment. In particular resin content in pine wood is considerably higher than other softwood species such as fir and spruce. Typical volatile organic compounds (VOCs) emitted from pine wood are terpenes of resin and aldehydes, which are considered to be products of the autoxidation of unsaturated fatty acids and their derivates (Risholm-Sundman et al. 1998, Wang et al. 1999). During the compounding process in the extruder between $180^{\circ} \mathrm{C}$ and $200{ }^{\circ} \mathrm{C}$, the VOCs of pine wood such as terpenes and their derivatives, $\alpha$-and $\beta$-pinene, low molecular weight aldehydes can cause microbubbles in compound granule or WPC deck. The microbubbles in the WPC product result in high water absorption in service. Furtheremore, the removal of water soluble components using cold and hot water extraction methods can improve the interface compatibility (adhesion and dispersion) between polar wood fiber and non-polar thermoplastics (Hosseiinaei et al. 2012b).

Thermoplastics, are non-polar (hydrophobic) substances, which are not compatible with polar (hydrophilic) wood flour and, therefore, poor adhesion between polymer and wood flour in WPC can result (Klason et al. 1984). In order to improve the affinity and adhesion between wood fibers and thermoplastic matrices in production, chemical coupling agents have been employed (Clemons 2002). The most commonly used compatibilizers of the wood/polymer interface are maleated polyolefins, acetic anhydride, monofunctional reactants, isocyanates or silanes. Effective methods to modify natural fibers chemically are graft copolymerization, acetylation/esterification of cellulose by a reaction with acetic anhydride or chemical treatment with sodium alginate and sodium hydroxide. Maleic anhydride grafted PP (MAPP) compatibilizer has been extensively used in wood fiber and polymer composites to improve the interface interaction between wood flour and plastic (Clemons 2002). The strong interfacial bonding between filler and polymer matrix caused by the compatibilizing agents (the MAPP chemically bonds with the $\mathrm{OH}$ groups in the lignocellulosic filler) limits the WA of composites. The compatibilizers improve the quality of adhesion between plastics and fibers to reduce the gaps in the interfacial region (Youngquist 1999). The anhydride groups in the MAPP enter into an esterification reaction with the surface hydroxyl groups of wood particles and covalently bond to the hydroxyl groups (Adhikary 2008). Although the above mentioned compatibilizers significantly improve the interface interaction between wood flour and plastic, they considerably increase the cost of WPC product.

The goal of this study was to analyze the dimensional stability of the WPCs made from polypropylene with wood flour with and without compatibilizing agent prepared from wood chips by extraction with cold and hot water for different durations. Softwood flour is extensively used in the production of WPC. Thus, pine wood flour as reinforcing filler was used in the production of WPCs in this study.

\section{MATERIALS AND METHODS}

\section{Materials}

Chips of southern yellow pine (Pinus spp.) wood with dimensions of 22-25 mm x 19-20 mm x 4-5 mm were supplied from a commercial MDF company. The chips with a moisture content of about $80 \%$ were immersed, respectively in boiling water for $1 \mathrm{~h}, 3 \mathrm{~h}$, and $5 \mathrm{~h}$ or in distilled water at room temperature $\left(25^{\circ} \mathrm{C}\right)$ for 1 day, 3 days, and 5 days. After the extraction process, the chips were dried at $80^{\circ} \mathrm{C}$ to reach approximately $20 \%$ moisture content based on the oven-dry weight of wood. The extracted chips were subsequently hammer milled to obtain a wood flour material $(60 \mathrm{mesh})$. The wood flour was dried in a laboratory oven at $100{ }^{\circ} \mathrm{C}$ for $24 \mathrm{~h}$ to moisture content of $1 \%$ before the compounding process.

Polypropylene (PP) $\left(\mathrm{MFI} / 230^{\circ} \mathrm{C} / 2,16 \mathrm{~kg}=5 \mathrm{~g} / 10 \mathrm{~min}\right.$, density: $\left.0,91 \mathrm{~g} / \mathrm{cm}^{3}\right)$ produced by Petkim Petrochemical Corporation in Turkey, was used as the polymeric material. The compatibilizing agent, maleic anhydride-grafted polypropylene (MAPP) $\left(O p t i m-425, \mathrm{MFI} / 190^{\circ} \mathrm{C} ; 2,16 \mathrm{~kg}=120 \mathrm{~g} / 10 \mathrm{~min}\right.$, density: 0,91 g/ $\left./ \mathrm{cm}^{3}\right)$, was supplied by Pluss Polymers Pvt. Ltd. in India. 


\section{Preparation of injection molded WPC specimens}

The wood flour (50 wt $\%$ ) was compounded with the polypropylene with and without the MAPP ( $3 \mathrm{wt} \%)$. The wood flour, polypropylene with and without MAPP granulates were processed in a $30 \mathrm{~mm}$ co-rotating twin-screw extruder with a length-to-diameter (L/D) ratio of 30:1. The barrel temperature of the extruder was controlled at 175$195^{\circ} \mathrm{C}$. The extruded strand passed through a water bath and was subsequently pelletized. The pellets were stored in a sealed container and then dried to the moisture content of $0-1 \%$ before the injection molding. The temperature used for injection molded specimens was $180-195^{\circ} \mathrm{C}$ from feed zone to die zone. The specimens were injected at injection pressure between 5 and $6 \mathrm{Mpa}$ with cooling time about $30 \mathrm{~s}$. Finally, the specimens were conditioned at a temperature of $23{ }^{\circ} \mathrm{C}$ and relative humidity of $50 \%$ according to ASTM D 618 (2008) Air-dry density values of the specimens varied from 1,01 to $1,03 \mathrm{~g} / \mathrm{cm}^{3}$. The raw material formulations of WPCs are presented in table 1 .

Table 1. Experimental design.

\begin{tabular}{|c|c|c|c|c|c|}
\hline \multirow{3}{*}{ WPC type } & \multirow{2}{*}{\multicolumn{3}{|c|}{$\begin{array}{l}\text { WPC composition } \\
\text { (by weight } \% \text { ) }\end{array}$}} & \multicolumn{2}{|c|}{ Treatment level of pine wood chips } \\
\hline & & & & \multirow{2}{*}{$\begin{array}{l}\text { Cold water } \\
\text { extraction } \\
\text { (day) }\end{array}$} & \multirow{2}{*}{$\begin{array}{l}\text { Hot water } \\
\text { extraction } \\
\text { (hour) }\end{array}$} \\
\hline & $\begin{array}{l}\text { Wood } \\
\text { flour }\end{array}$ & $\mathrm{PP}^{1}$ & $\mathrm{MAPP}^{2}$ & & \\
\hline A & 50 & 50 & 0 & 1 & - \\
\hline B & 50 & 50 & 0 & 3 & - \\
\hline $\mathrm{C}$ & 50 & 50 & 0 & 5 & - \\
\hline $\mathrm{D}$ & 50 & 47 & 3 & 1 & - \\
\hline E & 50 & 47 & 3 & 3 & - \\
\hline $\mathrm{F}$ & 50 & 47 & 3 & 5 & - \\
\hline G & 50 & 50 & 0 & - & 1 \\
\hline $\mathrm{H}$ & 50 & 50 & 0 & - & 3 \\
\hline İ & 50 & 50 & 0 & - & 5 \\
\hline $\mathrm{J}$ & 50 & 47 & 3 & - & 1 \\
\hline $\mathrm{K}$ & 50 & 47 & 3 & - & 3 \\
\hline $\mathrm{L}$ & 50 & 47 & 3 & - & 5 \\
\hline $\mathrm{M}$ & 50 & 50 & 0 & - & - \\
\hline $\mathrm{N}$ & 50 & 47 & 3 & - & - \\
\hline
\end{tabular}

${ }^{1}$ PP: polypropylene. ${ }^{2}$ MAPP: maleic anhydride-grafted polypropylene.

\section{Determination of dimensional stability}

The TS and WA tests were carried out according to ASTM D 570 (2010) specifications. The test specimens were in the form of a disk $50,8 \mathrm{~mm}$ in diameter and $3,2 \mathrm{~mm}$ in thickness. The conditioned specimens were entirely immersed for 1 day, 7 days, and 28 days in a container of water at $23 \pm 2^{\circ} \mathrm{C}$. At the end of each immersion time, the specimens were taken out from the water and all surface water was removed with a clean dry cloth. The specimens were weighed to the nearest $0,01 \mathrm{~g}$ and measured to the nearest $0,001 \mathrm{~mm}$ immediately. Six replicate specimens were tested for each WPC formulation.

The values of WA as percentages were calculated with Eq. 1:

$$
\mathrm{WA}_{\mathrm{t}}=\frac{\left(W_{t}-W_{o}\right)}{W_{o}} \times 100
$$


Where $\mathrm{WA}_{\mathrm{t}}$ is the water absorption (\%) at time $t, W_{0}$ is the initial weight of the specimen, and $W_{t}$ is the weight of the specimen at a given immersion time $t$. The values of TS as percentages were calculated with Eq. 2:

$$
\mathrm{TS}_{\mathrm{t}}=\frac{\left(T_{t}-T_{o}\right)}{T_{o}} \times 100
$$

Where $\mathrm{TS}_{t}$ is the thickness swelling (\%) at time $t, T_{0}$ is the initial thickness of the specimen, and $T_{t}$ is the thickness at time $t$.

\section{RESULTS AND DISCUSSION}

The dimensional stability of WPCs was improved with the cold or hot water extraction of wood chips. The TS and WA values of all the WPCs made using the extracted wood was lower than those of the ones with unextracted wood. The time dependence of TS and WA of all the WPCs is presented in figure 1. The effect of hot water extraction on the TS and WA properties of the WPCs was more pronunced than that of the cold water extraction. As compared to the uncoupled control WPC, the WA values (28 days) of uncoupled WPCs produced with wood extracted with cold water (5 days) or hot water extraction ( $5 \mathrm{~h}$ ) decreased by $4,1 \%$ and $6,2 \%$, respectively. A similar trend was found for the TS values. The TS and WA values of WPCs decreased with increasing cold or hot water extraction time. Significant differences $(\mathrm{p}<0,01)$ between some group averages for the TS and WA values are presented in Table 2 . No significant differences were found in the TS and WA values of the WPCs after 28 day immersion. The hot water extraction for $5 \mathrm{~h}$ showed the lowest TS and WA values for the WPCs while the highest TS and WA values were found for the the 1 day cold water extraction. In general, the TS and WA values of WPCs decreased considerably as the holding time for the hot water extraction increased to $3 \mathrm{~h}$ while this was observed as the holding time for the cold water extraction increased to 5 days.
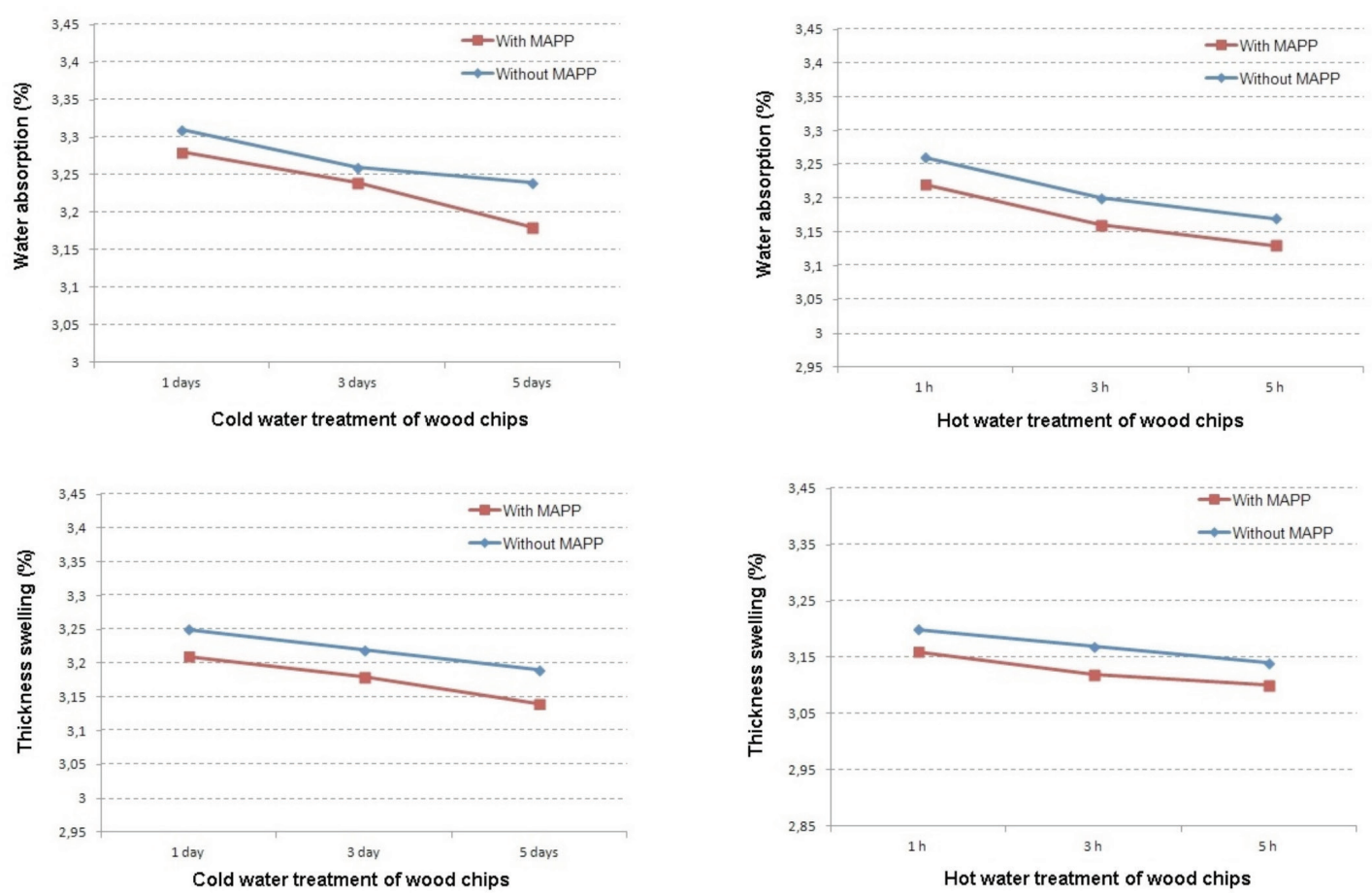

Figure 1. Thickness swelling (TS) and water absorption (WA) values of WPCs with and without MAPP as a function treatment type. 
The improvement in the TS and WA of WPCs was mainly attributed to the water-soluble components removed from the chips, in particular for the hot water treatment (Pelaez-Samaniego et al. 2012). Theoretically, the available $\mathrm{OH}$ groups in hemicellulose have the most significant effect on the physical properties of wood. As the wood chips were boiled in a container, the hemicelluloses are degraded to a greater extent than other polymers of wood such as water soluble materials, lignin, etc. (Stamm 1964). The random and amorphous structure of hemicellulose makes it easy to hydrolyze (Hu et al. 2008). During the hydrothermal treatment of pine wood chips by boiling in water, formation of organic acids, the production of acetic and formic acid from hemicelluloses contributes to a cellular breakdown production of condensable fractions, with loss of a high percentage of hemicelluloses, low percentage of lignin, and volatile extractives (Heller 2009).

The decrease in water uptake of the WPC in this work may be attributed to the enhanced interfacial adhesion between wood flour and polymer matrix, which can help to avoid the water penetration and reducing the hygroscopicity (Adhikary et al. 2007). This result was confirmed with Shebani et al. (2008) and in agreement with Mansour et al. (1998) The removal of a portion of hydrophilic material from the wood results in a comparatively greater proportion of hydrophobic material thereby increasing compatibility with thermoplastic resins.

Dimensional stability of the WPCs was moderately enhanced on using extractive-free wood. This was due to the chemical compositions of extractives. Hot water procedure removes a part of extraneous components, such as gums, resins, terpenes, starches, glycosides, saponins, and essential oils (Pettersen 1984). They can diffuse to the surface, thus blocking cells and reducing contact of the functional groups of coupling agent with the hydroxyl groups (-OH) of cellulosic material (Bledzki et al. 2005) The extractives can reduce adhesion at the interface, which causes inferior interfacial bonding strength of the WPC as compared to the ones containing the extracted (extractive-free) wood flour. The removal of cold water extractives caused less improvement in the TS and WA values of the WPCs than the removal of hot water extractives (Table 2).

The compatibilizing agent (MAPP) improved the interfacial adhesion between the hydrophobic polymer matrix and hydrophilic wood, which could help to avoid the water penetration and reducing the hygroscopicity (Table 2). For example, as $3 \mathrm{wt} \%$ MAPP was incorporated into the WPC, the WA values (28 days) of WPCs produced with hot water extracted wood decreased from 3,22 to $3,13 \%$. This was good consistent with previous studies (PelaezSamaniego et al. 2012, Shebani et al. 2012). For example, Pelaez-Samaniego et al. (2012) treated undebarked ponderosa pine chips by hot water extraction to modify the chemical composition. They reported that the extract was composed mainly of degradation products of hemicelluloses. In their study, WA and TS was reduced by $46 \%$ and $45 \%$, after $2520 \mathrm{~h}$ of immersion. The strong interfacial bonding between the filler and polymer matrix caused by the compatibilizing agents chemically bonds with the $\mathrm{OH}$ groups in the lignocellulosic filler) limits the water absorption of WPC (Adhikary 2008). The compatibilizing agents improve the quality of adhesion between plastics and wood flour to reduce the gaps in the interfacial region and to block the hydrophilic groups (Youngquist 1999). The anhydride groups in the MAPP enter into an esterification reaction with the surface hydroxyl groups of wood fibers and covalently bond to the hydroxyl groups (Adhikary 2008). The positive effect of MAPP on the TS and WA properties decreased with increasing the holding time, particularly in hot water extraction. This was mainly attributed to decreases in the water-soluble components and $\mathrm{OH}$ groups in hemicellulose. The TS and WA results showed that the interface compatibility between the wood surface and polypropylene without the MAPP was increased by the extraction of of pine wood particles (Table 2). In particular, hot water extraction decreased hydrophilic structure due to a certain amount of polar functional groups on the wood flour surface, which made wood surface more compatible with the polypropylene surface. The effect of hot water extraction on the compatibility was higher than that of cold water extraction. 
Table 2. Dimensional stability of the WPCs produced with the wood extracted with cold or hot water.

\begin{tabular}{|c|c|c|c|c|c|c|c|}
\hline \multirow{3}{*}{$\begin{array}{l}\text { WPC } \\
\text { type }\end{array}$} & \multirow{3}{*}{$\begin{array}{l}\text { Density } \\
\left(\mathrm{g} / \mathrm{cm}^{3}\right)\end{array}$} & \multicolumn{6}{|c|}{ Dimensional stability } \\
\hline & & \multicolumn{3}{|c|}{ Water absorption (\%) } & \multicolumn{3}{|c|}{ Thickness swelling (\%) } \\
\hline & & 1 day & 7 days & 28 days & 1 day & 7 days & 28 days \\
\hline A & $1,01(0,05)$ & $0,59(0,04) a b$ & $1,40(0,05)$ ac & $3,31(0,08) \mathrm{ns}$ & $0,44(0,03)$ abe & $1,36(0,01)$ ae & $3,25(0,07) \mathrm{ns}$ \\
\hline B & $1,01(0,04)$ & $0,55(0,01)$ abd & $1,37(0,02)$ ac & $3,26(0,07) \mathrm{ns}$ & $0,39(0,03)$ abe & $1,32(0,03)$ abe & $3,22(0,14) \mathrm{ns}$ \\
\hline $\mathrm{C}$ & $1,01(0,03)$ & $0,54(0,06)$ ad & $1,35(0,03) a b$ & $3,24(0,06)$ ns & $0,35(0,03) \mathrm{c}$ & $1,29(0,02) a b f$ & $3,19(0,06) \mathrm{ns}$ \\
\hline D & $1,02(0,01)$ & $0,53(0,02)$ ad & $1,38(0,03)$ acd & $3,28(0,04) \mathrm{ns}$ & $0,38(0,03) a b c$ & $1,31(0,03)$ abf & $3,21(0,04) \mathrm{ns}$ \\
\hline E & $1,02(0,04)$ & $0,50(0,04)$ ac & $1,34(0,01) a b$ & $3,24(0,06) \mathrm{ns}$ & $0,36(0,04) a b c$ & $1,28(0,03)$ abf & $3,18(0,02) \mathrm{ns}$ \\
\hline F & $1,02(0,02)$ & $0,48(0,03) \mathrm{c}$ & $1,31(0,07) \mathrm{b}$ & $3,18(0,01) \mathrm{ns}$ & $0,32(0,02) \mathrm{c}$ & $1,23(0,02) b c$ & $3,14(0,04) \mathrm{ns}$ \\
\hline G & $1,01(0,02)$ & $0,57(0,03) a b$ & $1,38(0,02)$ ac & $3,26(0,26) \mathrm{ns}$ & $0,38(0,02) a b c$ & $1,30(0,03)$ abf & $3,20(0,56) \mathrm{ns}$ \\
\hline $\mathrm{H}$ & $1,02(0,01)$ & $0,53(0,01) \mathrm{d}$ & $1,34(0,01) a b$ & $3,20(0,13) \mathrm{ns}$ & $0,36(0,02) a b c$ & $1,27(0,04) a b$ & $3,17(0,10) \mathrm{ns}$ \\
\hline I & $1,02(0,05)$ & $0,49(0,02)$ ac & $1,31(0,06) a b$ & $3,17(0,09)$ ns & $0,33(0,03) \mathrm{bc}$ & $1,22(0,06) a b c$ & $3,14(0,07) \mathrm{ns}$ \\
\hline $\mathrm{J}$ & $1,03(0,04)$ & $0,52(0,04) a b$ & $1,34(0,02) a b$ & $3,22(0,05) \mathrm{ns}$ & $0,36(0,04) a b c$ & $1,26(0,07) a b c$ & $3,16(0,04) \mathrm{ns}$ \\
\hline $\mathrm{K}$ & $1,01(0,03)$ & $0,46(0,03)$ cd & $1,29(0,06)$ bd & $3,16(0,06) \mathrm{ns}$ & $0,31(0,02) \mathrm{bc}$ & $1,21(0,06) b c$ & $3,12(0,13) \mathrm{ns}$ \\
\hline L & $1,01(0,01)$ & $0,42(0,03) \mathrm{c}$ & $1,22(0,07) \mathrm{b}$ & $3,13(0,14) \mathrm{ns}$ & $0,29(0,02) \mathrm{c}$ & $1,15(0,05) \mathrm{c}$ & $3,10(0,67) \mathrm{ns}$ \\
\hline $\mathrm{M}$ & $1,01(0,04)$ & $0,64(0,03) \mathrm{b}$ & $1,47(0,04) \mathrm{c}$ & $3,38(0,06)$ ns & $0,53(0,01) \mathrm{d}$ & $1,42(0,04) \mathrm{e}$ & $3,29(0,13) \mathrm{ns}$ \\
\hline $\mathrm{N}$ & $1,02(0,02)$ & $0,58(0,07) a b$ & $1,44(0,01) \mathrm{c}$ & $3,33(0,07) \mathrm{ns}$ & $0,48(0,04)$ de & $1,39(0,08)$ ef & $3,23(0,47) \mathrm{ns}$ \\
\hline
\end{tabular}

${ }^{1}$ Table 1 for WPC formulation.

Groups with same letters in column indicate that there is no statistical difference $(p<0,01)$ between the samples according to Duncan's multiply range test. ns: non significant. The values in the parentheses are standard deviations.

\section{CONCLUSIONS}

Based on the findings of of this study, it could be said that cold and hot water extraction of the wood chips improved considerably the dimensional stability of the WPCs. The effect of hot water extraction on the TS and WA properties of the WPCs was more pronounced than cold water extraction. The TS and WA values of the WPCs decreased with increasing extraction time. The MAPP improved the interfacial adhesion between the polymer matrix and wood, which increased the water resistance. In general, the TS and WA values of the WPCs decreased considerably as the holding time for the hot water extraction increased to $3 \mathrm{~h}$ but this was observed for the cold water extraction as the holding time increased to 5 days. Hot water treatment for $(3 \mathrm{~h})$ can be efficiently applied to pine wood chips to remove a part of resin and other hot water soluble extractives which can cause microbubbles in the compound at high temperatures during extrusion process. The effect of the hot water extraction on the compatibility between the wood and plastic was better than the effect of cold water extraction. The test results showed that hot water extracted pine wood was an efficient reinforcing filler for the polypropylene composites used in applications requiring high dimensional stability. 


\section{REFERENCES}

Adhikary, K.B.; Pang, S.; Staiger, M.P. 2007. Long-term moisture absorption and thickness swelling behaviour of recycled thermoplastics reinforced with Pinus radiata sawdust. Chemical Engineering Journal 142:190-198.

Adhikary, K.B. 2008. Development of wood flour recycled polymer composite panels as building materials. Ph.D. Thesis, University of Canterbury, New Zeland.

Andrusyk, L.; Oporto, G.S.; Gardner, D.J.; Neivandt D.J. 2008. Wood plastic composites manufactured from hot water extracted wood. Part I: Mechanical evaluation. In: Proceedings of the 51st International Convention of Society of Wood Science and Technology, 10-12 November 2008, Concepción, Chile.

ASTM International. 2008. Standard practice for conditioning plastics for testing, ASTM D618, West Conshohocken, PA.

ASTM International. 2010. Standard test method for water absorption of plastics, ASTM D570, West Conshohocken, PA.

Bledzki, A.K.; Letman, M.; Viksne, A.; Rence, L. 2005. A comparison of compounding processes and wood type for wood fibre-PP composites. Composites Part A-Applied Science and Manufacturing 36(6):789-797.

Clemons, C.M. 2002. wood-plastic composites in the United States: the interfacing of two industries. Forest Products Journal 52(6): 10-18.

Heller, JJP. 2009. The influence of hot water extraction on physical and mechanical properties of OSB. Ph.D. Thesis, University of Maine, Maine.

Hosseinaei, O.; Wang, S.; Taylor, AM.; Kim, JW. 2012a. Effect of hemicellulose extraction on water absorption and mold susceptibility of wood plastic composites. International Biodeteriation and Biodegratation 71: 29-35.

Hosseinaei, O.; Wang, S.; Enayati, A.A.; Rials, T.G. 2012b. Effects of hemicellulose extraction on properties of wood and wood-pastic composites. Composites Part A-Applied Science and Manufacturing 43(4):686-694.

Hu, G.; Heitmann, J.A.; Rojas, O.J. 2008. Feedstock pretreatment strategies for producing ethanol from wood bark and forest residues. Bioresources 3(1):270-294.

Iswanto, AP.; Febrianto, F.; Wahyudi, I.; Hwang WJ.; Lee, SH.; Kwon, J.H.; Kwon, SM.; Kim, NH.; Kondo, T. 2010. Effect of pre-treatment techniques on physical, mechanical and durability properties of oriendted strandboard made from sentang wood (Melia excelsa Jack). Journal of Faculty of Agriculture Kyushu University 55(2):371-377.

Klason, C.; Kubát J.; Strömvall, H.E. 1984. The efficiency of cellulosic fillers in common thermoplastics. Part I. Filling without processing aids or coupling agents. International Journal of Polymeric Materialsand Polymeric Biomaterials 10: 159-187.

Liu, S.; Lu, H.; Lei, Y.; Wood, C.D.; Amidon, T.E.; Liang, B.; Sun, R.; Scott, G.M. Nichol, D.; Ward, A. 2012. Chapter 22. Separation of Hemicellulose by Hot Water Extraction from Woody Biomass. Integrated Biorefineries Design, Analysis, and Optimization (Eds: Stuart PR and El-Halwagi MM) CRC Press, Boca Raton.

Mansour, OK.; Kamel, S.; Nassar, M.A. 1998. Lignocellulosic polymer composites IV. Journal of Applied Polymer Science 69:845-855. 
Paredes, J.J.; Jara, R.; Shaler, S.M.; Heiningen, AV. 2008. Influence of hot water extraction on the physical and mechanical behavior of OSB. Forests Products Journal 58(12):56-62.

Pelaez-Samaniego, MR.; Yadama, V.; Lowell, E.; Amidon TE., Chaffee, TL. 2012. Hot water extracted wood fiber for production of wood plastic composites (WPCs). Holzforschung 67(2):193-200.

Pettersen, RC. 1984. Chapter 2: The Chemical Composition of Wood. The Chemistry of Solid Wood (Ed. R.Rowell). ACS publications, Washington DC.

Shebani, AN.; Van Reenen, A.J.; Meincken, M. 2008. The effect of wood extractives on the thermal stability of different wood species. Thermochimica Acta 471:43-50.

Shebani, A.; Reenen, AV.; Meincken, M. 2012. Using extractive-free wood as a reinforcement in wood-LLDPE composites. Journal of Reinforced Plastics and Composites 31(4):225-232.

Stamm, AJ. 1964. Wood and cellulose science. Ronald Press, New York.

Risholm-Sundman, M.; Lundgren, M.; Vestin, E.; Herder, P. 1998. Emissions of acetic acid and other volatile organic compounds from different species of solid wood. Holz Als Roh Und Werkstoff 56:125-129.

Wang, W.; Gardner, DJ.; Baumann, MGD. 1999. Volatile organic compound hot-press emissions from southern pine furnish as a function of adhesive type. TAPPI International Environmental Conference, , Nashville, Tennessee, Opryland Hotel, 18-21 April 1999, Tappi Press, Atlanta, GA.

Youngquist, R. 1999. Chapter 10: Wood-based composites and panel Products. In: Wood Handbook. Wood as an Engineering Material. United States Department of Agriculture, Forest Service, Forest Products Laboratory, Madison WI. 